\title{
Efeito residual da adubação orgânica sobre a produtividade de milho em sistema agroflorestal ${ }^{1}$
}

\author{
Ailton F. dos Santos'², Rômulo S. C. Menezes ${ }^{3}$, Vânia S. Fraga ${ }^{4}$ \& Aldrin M. Pérez-Marin ${ }^{5}$
}

RESUMO

O objetivo deste trabalho foi estudar, ao longo de dois anos, o efeito residual da adubação orgânica com esterco ou biomassa de gliricídia sobre os nutrientes do solo e sobre a produtividade e acúmulo de nutrientes pelo milho cultivado isolado (SA) ou consorciado em aléias de gliricídia (CA). O trabalho foi desenvolvido em Esperança, PB instalado em parcelas subdivididas, arranjadas em blocos casualizados, em que os sistemas (CA) e (SA) corresponderam aos tratamentos principais e os tratamentos de adubação com esterco, gliricídia e as parcelas-controle, aos tratamentos secundários, com quatro repetições. A adubação com esterco demonstrou maior efeito residual sobre a produtividade do milho nas parcelas do tratamento SA. No sistema CA o efeito residual foi reduzido, provavelmente pela competição por água e nutrientes entre o milho e gliricídia, indicando maior necessidade de adubação neste tipo de sistema. Os teores de P, K, Ca e Mg do solo em ambos os sistemas e ao longo dos dois anos do estudo foram mais elevados nas parcelas adubadas com esterco.

Palavras-chave: esterco, gliricídia, aléias, região semiárida

\section{Residual effect of organic fertilization on maize yield in an agroforestry system}

\begin{abstract}
The objective of the present study was to evaluate, during a period of two years, the residual effects of organic fertilization with animal manure or gliridicia prunings on the fertility of soil and on productivity and nutrient accumulation by maize cultivated either isolated (SA) or intercropped within alleys of gliricidia (CA). The study was conducted during 2006 and 2007 in the Centro Agroecológico São Miguel, headquarters of the NGO AS-PTA, in Esperança, PB, Brazil. The experiment was established in a split-plot design, arranged in randomized blocks, with the type of cropping system (SA or CA) as the main treatments and the organic fertilization (animal manure, gliricidia prunings or control plots) as the secondary treatments, with four replications. The organic fertilization with animal manure led to a residual effect increasing maize productivity during the two years, but the fertilization with gliricidia prunings had no residual effect. The residual effect on maize productivity was more pronounced in the SA plots, compared to the plots with gliricidia alleys (CA). Probably, the lower residual effect within the CA system was due to the competition between maize and gliricidia for resources (nutrients, water and light), which indicates the need for higher rates or more frequent fertilizer applications in these systems. The contents of $\mathrm{P}, \mathrm{K}, \mathrm{Ca}$ and $\mathrm{Mg}$ in the soil was higher in the plots that received animal manure within both types of cropping systems.
\end{abstract}

Key words: animal manure, gliricidia, alley cropping, semi-arid region

${ }^{1}$ Trabalho extraído da dissertação de mestrado do primeiro autor, Universidade Federal da Paraíba

2 M.Sc. em Manejo do Solo e Água, Rua: Janúncio Balduíno, 231 CEP 58640-000, Junco do Seridó, PB. Fone: (83) 3464-1036. E-mail: ailton.agronomo@gmail.com

DEN/UFPE, Av. Prof. Luiz Freire 1000, CEP 50740-540, Recife, PE. Fone: (81) 2126 7970. E-mail: rmenezes@ufpe.br

${ }^{4}$ DSER/UFPB, Campus II, CEP 58320-000 Areia, PB. Fone: (83) 3362 2300. E-mail: vfraga@cca.ufpb.br

${ }^{5}$ INSA/MCT, Av. Floriano Peixoto 715, 2 andar, Centro, CEP 58400-165 Campina Grande, PB. Fone: (83) 2101 6400. E-mail: aldrin@insa.gov.br 


\section{INTRODUÇÃO}

Na região do Agreste paraibano há predominância da agricultura familiar em relação aos outros sistemas agrários. As principais culturas agrícolas usadas nesses sistemas são o milho, o feijão e a mandioca, quase sempre associados a uma pequena atividade pecuária (Silva et al., 2007).

Os sistemas de cultivo agrícola são caracterizados pela contínua retirada da produção sem práticas que reponham os nutrientes retirados pelas plantas, o que causa deterioração das características físicas, químicas e biológicas dos solos em decorrência da redução dos teores de matéria orgânica e dos nutrientes (Perez-Marin et al., 2006).

O emprego de fertilizantes químicos nesses sistemas é muito reduzido devido ao custo dos fertilizantes e ao risco proporcionado pela variabilidade do regime de chuvas (Sampaio et al., 1995). Por este motivo, o manejo da fertilidade do solo da região depende principalmente do manejo da matéria orgânica (Tiessen et al., 1992).

Uma prática comumente adotada para aumentar a produção é o uso do esterco como adubo orgânico para o suprimento de N e P nos solos (Menezes \& Silva, 2008); no entanto, devido à reduzida disponibilidade de esterco nas propriedades rurais do agreste, os agricultores necessitam comprar esterco de regiões circunvizinhas, o que eleva o custo de produção (Menezes et al., 2002).

Como alternativa para contornar esse problema vem sendo adotada a prática da adubação verde, através do cultivo e uso de leguminosas arbóreas dentro dos sistemas agrícolas familiares. A gliricídia (Gliricidia sepium) é uma das espécies mais utilizadas, em virtude da sua rusticidade, elevada produção de matéria seca em condições de baixa disponibilidade hídrica e alta capacidade de fixar nitrogênio atmosférico, além de ser utilizada como forragem e lenha (Araújo \& Almeida, 1993; PerezMarin et al., 2006; 2007).

Uma das formas de cultivo da gliricídia é em sistema de aléias, o qual se baseia em plantios de fileiras de árvores suficientemente espaçadas, para permitir o plantio de culturas agrícolas entre elas (Sanchez, 1995). O manejo desse sistema é baseado em cortes periódicos da parte aérea das espécies arbóreas e na utilização da biomassa na alimentação animal e/ ou para incorporação ao solo, como adubo verde (Perez-Marin et al., 2006; 2007).

Neste sentido, um importante aspecto a ser considerado quando se estuda o efeito de adubos sobre a fertilidade do solo, especialmente os adubos orgânicos, é o efeito residual da adubação anterior na produtividade das culturas uma vez que o custo e a baixa disponibilidade de adubos não permitem a fertilização anual dos solos e assim sendo, o presente estudo teve como objetivo estudar, ao longo de dois anos, o efeito residual da adubação orgânica com esterco ou biomassa de gliricídia sobre a produtividade de milho isolado ou consorciado em aléias de gliricídia, a absorção e o acúmulo de nutrientes pelas diferentes partes do milho, e os teores de nutrientes do solo.

\section{Material E MÉTODOS}

\section{Descrição da área de estudo e histórico de manejo}

O trabalho foi desenvolvido nos anos de 2006 e 2007 no Centro Agroecológico São Miguel (CASM), sede da ONG Assessoria e Serviços a Projetos de Agricultura Alternativa (AS-PTA), no município de Esperança, no Agreste paraibano. O CASM está localizado a $7^{\circ} 19^{\prime}$ de latitude sul e $33^{\circ} 51^{\prime}$ de longitude oeste, a uma altitude de $635 \mathrm{~m}$. O clima da região se caracteriza por apresentar uma estação chuvosa, de março a agosto, e uma estação seca, de setembro a fevereiro.

A precipitação pluviométrica média anual é cerca de 800 $\mathrm{mm}$, e os totais anuais em 2006 e 2007 atingiram 642 e 559 mm, respectivamente. O solo na área experimental é um Neossolo Regolítico, com declividade em torno de $0,05 \mathrm{~m} \mathrm{~m}^{-1}$, textura franco- arenosa (Perez-Marin et al., 2006).

Nesta área, fileiras de gliricídia foram plantadas em 1996, em uma área de aproximadamente 0,5 ha, com o espaçamento de 6 $\mathrm{m}$ entre fileiras e $1 \mathrm{~m}$ entre as plantas. Em 2003 foram demarcadas, dentro da área experimental, quatro parcelas de $144 \mathrm{~m}^{2}$ cada uma $(6 \times 24 \mathrm{~m})$, que corresponderam ao tratamento com aléias de gliricídia consorciadas com milho (CA). Imediatamente adjacente a essas parcelas, em áreas sem gliricídia foram estabelecidas parcelas de mesmo tamanho, nas quais foi cultivado o milho solteiro em sistema convencional (SA).

Cada parcela dos tratamentos principais (CA e SA) foi subdividida em três parcelas de $48 \mathrm{~m}^{2}(6 \times 8 \mathrm{~m})$, nas quais foram implementados três tratamentos secundários de adubação orgânica: 1$)$ aplicação de $15 \mathrm{t} \mathrm{ha}^{-1}$ de massa seca $\left(\approx 20 \mathrm{t} \mathrm{ha}^{-1}\right.$ massa fresca) de esterco (E); 2) aplicação de 6,40 tha ${ }^{-1}$ de massa seca $\left(\approx 20 \mathrm{t} \mathrm{ha}^{-1}\right.$ massa fresca) de gliricídia (folhas e galhos finos fragmentados) (G) e 3) controle (T), sem nenhum tipo de adubação orgânica. As parcelas receberam os tratamentos de adubação orgânica entre os anos de 2003 a 2005, objetivandose estudar o efeito da adubação sobre a produtividade do milho (Perez-Marin et al., 2007).

O presente estudo foi então conduzido nos anos de 2006 a 2007, nas mesmas parcelas experimentais, para quantificar o efeito residual da adubação prévia com esterco e gliricídia.

\section{Plantio, manejo e colheita do milho}

O milho foi plantado nos anos de 2006 a 2007, em março e abril, respectivamente logo após o inicio do período chuvoso. Cultivou-se a variedade local catingueirinha, proveniente do banco de sementes da AS-PTA. Duas sementes por cova foram plantadas com espaçamento de 1 x 0,20 m. Aproximadamente duas semanas após a emergência das plântulas realizou-se o desbaste, deixando-se uma planta por cova (50.000 plantas ha $^{-1}$ no sistemas sem aléias e 41.500 plantas $\mathrm{ha}^{-1}$ no sistema com aléias).

O controle de plantas espontâneas foi realizado com enxada, uma vez em cada ano, cerca de 20 dias após a semeadura do milho.

Realizou-se a colheita do milho aproximadamente aos 120 dias após a semeadura, sendo as plantas separadas em: palhada (colmo + folhas), grãos, sabugo e palha da espiga. Esses componentes foram pesados, subamostras foram retiradas e, 
posteriormente, secadas em estufa a $65^{\circ} \mathrm{C}$, até atingir peso constante para determinação da matéria seca.

Calculou-se a produtividade da biomassa das partes do milho com base nas amostras retiradas para determinação da matéria seca, no peso total de cada parte e na área plantada com o milho, cujos resultados foram expressos em $\mathrm{kg} \mathrm{ha}^{-1}$ de matéria seca.

\section{Manejo da gliricídia}

No ano de 2006 não houve necessidade de poda nas árvores de gliricídia uma vez que foi realizada uma poda no final do ano de 2005 e, deste modo, constatou-se que o porte das árvores não atrapalharia o desenvolvimento do milho em 2006; entretanto, no ano de 2007, antes do plantio do milho, uma poda nas árvores de gliricídia foi realizada, e o material podado (folhas e galhos) foi retirado da área experimental e destinado à alimentação animal.

\section{Análises químicas das amostras de milho e do solo}

Para determinar os teores de $\mathrm{P}, \mathrm{K}, \mathrm{Ca}$ e $\mathrm{Mg}$ nas diferentes partes do milho (palhada, grãos, sabugo e palha da espiga), amostras de $0,25 \mathrm{~g}$ desses materiais foram digeridas em uma mistura de $\mathrm{H}_{2} \mathrm{SO}_{4}+\mathrm{H}_{2} \mathrm{O}_{2}$ (EMBRAPA, 1999). Nos extratos, se determinaram os teores de $\mathrm{K}$ por fotometria de chama, de $\mathrm{P}$ por colorimetria, Ca e Mg por absorção atômica (EMBRAPA, 1999); as análises das amostras vegetais foram realizadas no Laboratório de Fertilidade do Solo do Departamento de Energia Nuclear da Universidade Federal do Pernambuco.

Para determinação da fertilidade do solo, se retiraram, em cada parcela experimental e ao final de cada ciclo de cultivo do milho, três amostras simples de solo na profundidade de 0-20 $\mathrm{cm}$, as quais foram misturadas para formar uma amostra composta. Essas amostras foram levadas para o Laboratório de Matéria Orgânica do Departamento de Solos e Engenharia Rural da Universidade Federal da Paraíba. O solo foi secado à sombra e passado em peneira de $2 \mathrm{~mm}$, formando a terra fina secada ao ar (TFSA).

Visando a determinação de P e K extraíveis, utilizou-se a solução extratora Mehlich-1, seguida da determinação do P por colorimetria e do K por fotometria de chama (EMBRAPA, 1999). O Ca e o Mg trocáveis foram extraídos por $\mathrm{KCl} 1 \mathrm{M} \mathrm{e}$ determinados por complexometria com EDTA, usando-se como indicador o negro-de-eriocromo - $\mathrm{T}$. O teor de $\mathrm{Mg}$ foi determinado pela diferença entre as leituras de $\mathrm{Ca}+\mathrm{Mg}$ menos a leitura de $\mathrm{Ca}$.

\section{Análises estatísticas}

Os resultados da produtividade do milho, absorção e acúmulo de nutrientes, foram tratados estatisticamente pela análise de variância, segundo o delineamento em blocos casualizados em parcelas subdivididas, e as médias comparadas pelo teste de Tukey a $5 \%$ de probabilidade. Os dados foram analisados com o programa estatístico SAS (SAS, 2000).

\section{RESULTADOS E DISCUSSÃO}

\section{Produtividade do milho}

De maneira geral, em ambos os sistemas, sem aléias (SA) e com aléias (CA), a adubação orgânica com esterco exerceu maior efeito residual sobre a produtividade de biomassa do milho, nos dois anos do estudo, em comparação com a adubação orgânica com gliricídia (Tabela 1).

Tabela 1. Produtividade $\left(\mathrm{kg} \mathrm{ha}^{-1}\right)$ de matéria seca de grãos, palha de milho, sabugo, palha da espiga e de vegetação nativa espontânea, em parcelas cultivadas com e sem aléias de gliricídia, nos primeiro e segundo anos após a última adubação orgânica com esterco ou gliricídia

\begin{tabular}{|c|c|c|c|c|}
\hline $\begin{array}{c}\text { Sistema } \\
\text { de cultivo }\end{array}$ & $\begin{array}{c}\text { Adubação } \\
\text { orgânica }\end{array}$ & 2006 & 2007 & $\begin{array}{l}\text { Média } \\
\text { anual }\end{array}$ \\
\hline \multirow{4}{*}{ SA } & & Grãos & & \\
\hline & Esterco & $2.001 \mathrm{a}$ & $1.170 \mathrm{a}$ & 1586 \\
\hline & Gliricídia & $1.351 \mathrm{~b}$ & $603 \mathrm{a}$ & 977 \\
\hline & Controle & $1.020 \mathrm{~b}$ & $300 \mathrm{a}$ & 660 \\
\hline \multirow[t]{3}{*}{ CA } & Esterco & $396 \mathrm{a}$ & $267 \mathrm{a}$ & 332 \\
\hline & Gliricídia & $123 b$ & $36 \mathrm{a}$ & 80 \\
\hline & Controle & $48 \mathrm{~b}$ & $15 a$ & 32 \\
\hline \multicolumn{5}{|c|}{ Palhada } \\
\hline \multirow[t]{3}{*}{ SA } & Esterco & $2.161 \mathrm{a}$ & $665 a$ & 1413 \\
\hline & Gliricídia & $1.895 \mathrm{a}$ & $417 \mathrm{ab}$ & 1156 \\
\hline & Controle & $1.755 \mathrm{a}$ & $398 \mathrm{~b}$ & 1077 \\
\hline \multirow[t]{3}{*}{ CA } & Esterco & $567 \mathrm{a}$ & $267 \mathrm{a}$ & 417 \\
\hline & Gliricídia & $579 \mathrm{a}$ & $168 \mathrm{ab}$ & 374 \\
\hline & Controle & $173 \mathrm{a}$ & $136 \mathrm{~b}$ & 155 \\
\hline \multicolumn{5}{|c|}{ Vegetação espontânea } \\
\hline \multirow[t]{3}{*}{ SA } & Esterco & $1250 \mathrm{a}$ & $706 \mathrm{a}$ & 978 \\
\hline & Gliricídia & $820 \mathrm{ab}$ & $490 \mathrm{a}$ & 655 \\
\hline & Controle & $590 \mathrm{~b}$ & $552 \mathrm{a}$ & 571 \\
\hline \multirow[t]{3}{*}{ CA } & Esterco & $237 \mathrm{a}$ & 331 a & 245 \\
\hline & Gliricídia & $223 a b$ & $273 \mathrm{a}$ & 248 \\
\hline & Controle & 214 b & $235 \mathrm{a}$ & 225 \\
\hline
\end{tabular}
pelo teste de Tukey a $5 \%$ de probabilidade

No sistema SA o efeito residual sobre as produtividades de grãos nas parcelas adubadas com esterco, nos primeiro e segundo anos, foi 48 e $98 \%$ maior que o tratamento com gliricídia, e 96 e $240 \%$ maior que o tratamento controle. No tratamento com gliricídia as produtividades de grãos foram 32 e 101\% maiores em relação ao tratamento controle em 2006 e 2007, respectivamente, mas não houve diferenças estatisticamente significativas (Tabela 1).

Em geral, o efeito residual da adubação orgânica foi maior no primeiro ano em comparação com o segundo, o que pode ser verificado na produtividade média de grãos, que foi $71 \mathrm{e}$ $124 \%$ maior, quando incorporados esterco e gliricídia, respectivamente, o que era previsto, devido à maior disponibilidade de nutrientes naquele ano. Resultados similares também foram observados quanto à produtividade da palhada e da vegetação nativa espontânea. Em média, ao longo dos dois anos do estudo as parcelas adubadas com esterco em relação ao controle produziram $926,337 \mathrm{e} 407 \mathrm{~kg} \mathrm{ha}^{-1}$ a mais de massa de matéria seca de grãos, palhada do milho e de vegetação nativa, respectivamente (Tabela 1).

A produtividade de biomassa média anual nas parcelas adubadas com esterco e gliricídia foi 52 e 144\% menor em comparação com a produtividade média de biomassa no período de três anos em que as parcelas receberam adubação orgânica (Perez-Marin et al., 2007). 
No sistema CA a produtividade de grãos nas parcelas adubadas com esterco nos primeiro e segundo anos foi 222 e $642 \%$ maior que nas parcelas adubadas com gliricídia e 725 e $1.680 \%$ maior que nas parcelas testemunha, respectivamente. Por outro lado, as produtividades de grãos nas parcelas adubadas com gliricídia em 2006 e 2007 foram 156 e $140 \%$ maiores que nas parcelas testemunha, respectivamente.

Ao longo de todo o período avaliado as produtividades médias de grãos, palhada do milho e vegetação nativa espontânea, após a incorporação de esterco, foram cerca de 300, 263, e $229 \mathrm{~kg} \mathrm{ha}^{-1}$ superiores ao tratamento controle, respectivamente. A menor produtividade de biomassa de milho quantificada no sistema $\mathrm{CA}$, se deve à forte competição por água e nutrientes, conforme demonstrado por Pérez-Marin et al. (2007).

O maior efeito residual do esterco se deve principalmente a dois fatores: em primeiro lugar, à adubação com esterco que no período de 2003 a 2005 adicionou, ao solo, cerca de 103 e 585 $\mathrm{kg} \mathrm{ha}^{-1}$ de $\mathrm{P}$ e K, respectivamente, em comparação com a adição de 46 e $538 \mathrm{~kg} \mathrm{ha}^{-1}$ de P e K, com a incorporação da gliricídia (Pérez-Marin et al., 2007). Como o P é um dos três elementos mais limitantes para o crescimento vegetal em solos do semiárido, a dose duas vezes maior na adubação com esterco pode ter proporcionado maior desenvolvimento do milho (Sampaio et al., 1995). Em segundo lugar, o esterco se decompõe mais lentamente que a gliricídia proporcionando maior armazenamento de nutrientes no solo e, por sua vez, maior efeito residual nos anos subsequentes à adubação (Silva et al., 2007; Menezes \& Salcedo, 2007; Mundus et al., 2008).

Em resumo, os resultados mostram que a incorporação de esterco no sistema SA promoveu aumento significativo da produtividade do milho, mas a incorporação de gliricídia não demonstrou esse efeito residual, sugerindo que não seria necessária a aplicação anual do esterco nessas áreas, permitindo uma rotação na aplicação de esterco nos campos agrícolas, o que é importante em razão da disponibilidade limitada de esterco para adubação nas propriedades rurais.

No sistema CA o efeito residual foi comprometido pela competição por água e nutrientes pelo milho e as árvores de gliricídia, indicando uma necessidade maior de adubação nesse tipo de sistema uma vez que, além da colheita do milho, há também a retirada da biomassa da gliricídia para uso como forragem, o que diminui ainda mais a disponibilidade de nutrientes no solo.

É importante destacar que o processo de ciclagem de nutrientes através de outros processos, tais como queda de folhedo e morte de raízes, não foi suficiente para atender à demanda nutricional do milho nas parcelas agroflorestais nesse estudo, como demonstrado também por Pérez-Marin et al. (2006).

\section{Absorção e acúmulo pelo milho}

O milho cultivado no sistema SA apresentou maior biomassa e, portanto, absorveu e acumulou mais nutrientes em relação ao sistema CA (Tabela 2). Tanto no sistema SA quanto no sistema $\mathrm{CA}$, o milho alocou a maior quantidade de nutrientes (P, K, Ca e Mg) para a palhada, seguida dos grãos, sabugo e palha da espiga. Em média, no sistema CA a palhada continha, nos primeiro e segundo anos, cerca de 56 e $63 \%$ dos nutrientes absorvidos pelo milho, respectivamente. No sistema SA, a palhada continha nos primeiro e segundo anos, cerca de 49 e $52 \%$ dos nutrientes acumulados pelo milho e os grãos cerca de 32 e $27 \%$, respectivamente. Em ambos os sistemas e ao longo do período de estudo cerca de 43 e $22 \%$ dos nutrientes contidos na palhada e grãos do milho eram compostos de $\mathrm{K}$ e $\mathrm{Ca}$,

Tabela 2. Absorção, acúmulo e distribuição (em kg ha-1) de P, K, Ca e Mg nas diferentes partes do milho em parcelas cultivadas com (CA) e sem aléias (SA) de gliricídia, nos primeiro e segundo anos após a última adubação orgânica com esterco ou gliricídia

\begin{tabular}{|c|c|c|c|c|c|c|}
\hline \multirow{2}{*}{ Nutrientes } & \multicolumn{3}{|c|}{ Sistema CA } & \multicolumn{3}{|c|}{ Sistema SA } \\
\hline & Esterco & Gliricídia & Controle & Esterco & Gliricídia & Controle \\
\hline & \multicolumn{6}{|c|}{$\begin{array}{c}2006 \\
\text { *Palhada }\end{array}$} \\
\hline P & 0,66 & 0,65 & 0,65 & 1,60 & 2,07 & 0,97 \\
\hline K & 4,39 & 4,8 & 0,70 & 14,03 & 14,12 & 8,86 \\
\hline $\mathrm{Ca}$ & 3,28 & 1,77 & 2,22 & 7,58 & 8,06 & 6,90 \\
\hline \multirow[t]{2}{*}{$\mathrm{Mg}$} & 1,79 & 1,50 & 0,37 & 6,91 & 6,40 & 5,60 \\
\hline & \multicolumn{6}{|c|}{ Grãos } \\
\hline $\mathrm{P}$ & $0,80 \mathrm{a}$ & $0,18 a b$ & $0,07 \mathrm{~b}$ & $3,52 \mathrm{a}$ & $1,73 a b$ & 0,77 b \\
\hline K & $0,71 \mathrm{a}$ & $0,59 a$ & $0,14 \mathrm{a}$ & $7,14 \mathrm{a}$ & $6,95 \mathrm{a}$ & $4,54 \mathrm{a}$ \\
\hline $\mathrm{Ca}$ & $2,13 \mathrm{a}$ & $0,78 \mathrm{a}$ & $0,21 \mathrm{~b}$ & $9,06 \mathrm{a}$ & $6,63 a b$ & $5,38 \mathrm{~b}$ \\
\hline \multirow[t]{2}{*}{$\mathrm{Mg}$} & $0,88 \mathrm{a}$ & $0,26 \mathrm{a}$ & $0,08 \mathrm{~b}$ & $4,54 \mathrm{a}$ & $2,88 \mathrm{a}$ & $1,85 \mathrm{a}$ \\
\hline & \multicolumn{6}{|c|}{${ }^{\star}$ Sabugo } \\
\hline P & 0,22 & 0,17 & 0,12 & 0,42 & 0,45 & 0,23 \\
\hline K & 2,79 & 1,63 & 0,91 & 2,65 & 5,76 & 2,60 \\
\hline $\mathrm{Ca}$ & 0,14 & 0,13 & 0,04 & 0,23 & 0,38 & 0,22 \\
\hline \multirow[t]{2}{*}{$\mathrm{Mg}$} & 0,10 & 0,14 & 0,10 & 0,17 & 0,12 & 0,06 \\
\hline & \multicolumn{6}{|c|}{ *Palha da espiga } \\
\hline P & 0,33 & 0,17 & 0,06 & 0,42 & 0,28 & 0,37 \\
\hline K & 1,87 & 1,98 & 0,42 & 5,74 & 4,28 & 3,09 \\
\hline $\mathrm{Ca}$ & 0,46 & 0,35 & 0,10 & 1,38 & 0,99 & 0,94 \\
\hline $\mathrm{Mg}$ & 0,37 & 0,27 & 0,09 & 1,03 & 0,70 & 0,60 \\
\hline Total & 20.9 & 15.4 & 6.3 & 66.4 & 61.8 & 43.0 \\
\hline $\mathrm{BT}^{1}$ & 1398 & 1079 & 333 & 5292 & 4409 & 3637 \\
\hline \multirow[t]{3}{*}{$\mathrm{CUB}^{2}$} & 67 & 70 & 53 & 80 & 71 & 85 \\
\hline & \multirow{2}{*}{\multicolumn{6}{|c|}{$\begin{array}{l}2007 \\
\text { Palhada }\end{array}$}} \\
\hline & & & & & & \\
\hline$P$ & $0,71 \mathrm{a}$ & $0,44 \mathrm{a}$ & $0,30 \mathrm{~b}$ & $1,87 \mathrm{a}$ & $0,72 b$ & $0,96 \mathrm{~b}$ \\
\hline K & $2,13 a$ & $1,29 a$ & $0,87 \mathrm{~b}$ & $4,97 \mathrm{a}$ & $3,23 \mathrm{a}$ & $2,92, a$ \\
\hline $\mathrm{Ca}$ & $1,13 \mathrm{a}$ & $0,69 \mathrm{a}$ & $0,31 \mathrm{~b}$ & $2,41 \mathrm{a}$ & $0,97^{a}$ & $1,24 \mathrm{a}$ \\
\hline \multirow[t]{2}{*}{$\mathrm{Mg}$} & $0,56 \mathrm{a}$ & $0,29 a b$ & $0,21 b$ & $1,17 \mathrm{a}$ & $0,58 \mathrm{~b}$ & $0,60 \mathrm{~b}$ \\
\hline & \multicolumn{6}{|c|}{ *Grãos } \\
\hline $\mathrm{P}$ & 1,01 & 0,125 & 0,05 & 2,90 & 2,97 & 0,93 \\
\hline K & 0,06 & 0,01 & 0,01 & 0,24 & 0,23 & 0,07 \\
\hline $\mathrm{Ca}$ & 0,15 & 0,02 & 0,01 & 1,80 & 0,36 & 0,17 \\
\hline \multirow[t]{2}{*}{$\mathrm{Mg}$} & 0,30 & 0,05 & 0,02 & 1,09 & 0,87 & 0,27 \\
\hline & \multicolumn{6}{|c|}{ *Sabugo } \\
\hline $\mathrm{P}$ & 0,11 & 0,04 & 0,03 & 0,165 & 0,11 & 0,11 \\
\hline K & 0,43 & 0,17 & 0,09 & 0,11 & 0,76 & 0,73 \\
\hline $\mathrm{Ca}$ & 0,05 & 0,011 & 0,01 & 0,19 & 0,08 & 0,08 \\
\hline \multirow[t]{2}{*}{$\mathrm{Mg}$} & 0,02 & 0,01 & 0,01 & 0,05 & 0,03 & 0,03 \\
\hline & \multicolumn{6}{|c|}{ Palha da espiga } \\
\hline$P$ & $0,71 \mathrm{a}$ & $0,13 \mathrm{~b}$ & $0,10 \mathrm{~b}$ & $0,44 \mathrm{a}$ & $0,22 \mathrm{~b}$ & $0,33 \mathrm{~b}$ \\
\hline K & $1,05 \mathrm{a}$ & $0,51 \mathrm{~b}$ & $0,32 \mathrm{~b}$ & $1,78 a$ & $0,62 \mathrm{~b}$ & $0,97 \mathrm{~b}$ \\
\hline $\mathrm{Ca}$ & $0,22 \mathrm{a}$ & $0,05 \mathrm{a}$ & $0,03 \mathrm{a}$ & $0,40 \mathrm{a}$ & $0,67 \mathrm{a}$ & $0,14 a$ \\
\hline $\mathrm{Mg}$ & $0,17 \mathrm{a}$ & $0,10 \mathrm{~b}$ & $0,06 \mathrm{~b}$ & $0,28 \mathrm{a}$ & $0,10 \mathrm{~b}$ & $0,12 \mathrm{~b}$ \\
\hline Total & 8.81 & 3.936 & 2.43 & 19.865 & 12.52 & 9.67 \\
\hline BT & 725 & 298 & 219 & 2187 & 1208 & 888 \\
\hline CUB & 82 & 76 & 90 & 110 & 96 & 92 \\
\hline
\end{tabular}

Valores seguidos de mesmas letras minúsculas nas linhas são iguais estatisticamente em relação às adubações, pelo teste de Tukey a $5 \%$ de probabilidade. ${ }^{*}$ Não significativo. ${ }^{1} \mathrm{BT}=$ Biomassa total produzida pelo milho, considerando-se as diferentes partes. ${ }^{2} \mathrm{CUB}=$ Coeficiente de Utilização Biológica, que corresponde a relação entre a quantidade de biomassa produzida/quantidade de nutrientes absorvidos 
Tabela 3. Teores de fósforo $(\mathrm{P})$, potássio $(\mathrm{K})$, cálcio $(\mathrm{Ca})$ e magnésio $(\mathrm{Mg})$ de um Neossolo Regolítico em sistema de cultivo com ou sem gliricídia, nos primeiro e segundo anos após a última adubação orgânica com esterco ou gliricídia

\begin{tabular}{|c|c|c|c|c|c|c|}
\hline \multirow{2}{*}{ Nutrientes } & \multicolumn{3}{|c|}{ Sistema com aléias (CA) } & \multicolumn{3}{|c|}{ Sistema sem aléias (SA) } \\
\hline & Esterco & Gliricídia & Controle & Esterco & Gliricídia & Controle \\
\hline $\begin{array}{c}\mathrm{P}\left(\mathrm{mg} \mathrm{dm}^{-3}\right) \\
\mathrm{K}\left(\mathrm{mg} \mathrm{dm}^{-3}\right) \\
\mathrm{Ca}\left(\mathrm{cmol}_{\mathrm{c}} \mathrm{dm}^{-3}\right) \\
\mathrm{Mg}\left(\mathrm{cmol}_{\mathrm{c}} \mathrm{dm}^{-3}\right) \\
\mathrm{CTC}\end{array}$ & $\begin{array}{c}19,4 \mathrm{a} \\
93,3 \mathrm{ab} \\
2,9 \mathrm{a} \\
1,0 \mathrm{a} \\
4,1 \\
\end{array}$ & $\begin{array}{c}7,5 \mathrm{ab} \\
105,8 \mathrm{a} \\
1,8 \mathrm{~b} \\
0,7 \mathrm{a} \\
2,7\end{array}$ & $\begin{array}{c}5,3 \mathrm{~b} \\
57,5 \mathrm{~b} \\
1,5 \mathrm{~b} \\
0,5 \mathrm{a} \\
2,1 \\
\end{array}$ & $\begin{array}{c}10,3 \mathrm{a} \\
85,5 \mathrm{ab} \\
3,0 \mathrm{a} \\
1,0 \mathrm{a} \\
4,2 \\
\end{array}$ & $\begin{array}{c}8,1 \mathrm{ab} \\
130,7 \mathrm{a} \\
2,2 \mathrm{~b} \\
0,9 \mathrm{a} \\
3,4\end{array}$ & $\begin{array}{c}7,4 \mathrm{~b} \\
76,2 \mathrm{~b} \\
2,1 \mathrm{~b} \\
0,9 \mathrm{a} \\
3,2\end{array}$ \\
\hline $\begin{array}{c}\mathrm{P}\left(\mathrm{mg} \mathrm{dm}^{-3}\right) \\
\mathrm{K}\left(\mathrm{mg} \mathrm{dm}^{-3}\right) \\
\mathrm{Ca}\left(\mathrm{cmol}_{\mathrm{c}} \mathrm{dm}^{-3}\right) \\
\mathrm{Mg}\left(\mathrm{cmol}_{\mathrm{C}} \mathrm{dm}^{-3}\right) \\
\text { CTC }\end{array}$ & $\begin{array}{c}9,9 \mathrm{a} \\
97,3 \mathrm{a} \\
1,13 \mathrm{a} \\
0,47 \mathrm{a} \\
1,8\end{array}$ & $\begin{array}{c}4,9 a b \\
82 \mathrm{a} \\
0,5 \mathrm{~b} \\
0,75 \mathrm{a} \\
1,5\end{array}$ & $\begin{array}{c}4,5 \mathrm{~b} \\
74,6 \mathrm{a} \\
0,61 \mathrm{~b} \\
0,45 \mathrm{a} \\
1,3\end{array}$ & $\begin{array}{c}10,3 \mathrm{a} \\
104,7 \mathrm{a} \\
1,23 \mathrm{a} \\
0,13 \mathrm{a} \\
1,6\end{array}$ & $\begin{array}{c}8,7 \mathrm{ab} \\
117,2 \mathrm{a} \\
0,97 \mathrm{~b} \\
0,38 \mathrm{a} \\
1,6\end{array}$ & $\begin{array}{c}7,5 \mathrm{~b} \\
79,9 \mathrm{a} \\
0,69 \mathrm{~b} \\
0,52 \mathrm{a} \\
1,4\end{array}$ \\
\hline
\end{tabular}

Valores seguidos de letras minúsculas iguais na linha não diferem estatisticamente em relação às adubações pelo teste de Tukey a $5 \%$ de probabilidade

CTC- Capacidade de Troca Catiônica

respectivamente. Assim, a utilização da palha para alimentação animal sem o retorno do esterco por eles produzido, representa um forte dreno das reservas de $\mathrm{K}$ e $\mathrm{Ca}$ do solo.

As quantidades de $\mathrm{P}, \mathrm{K}, \mathrm{Ca}$ e $\mathrm{Mg}$ absorvidos pelo milho em ambos os sistemas e ao longo dos dois anos de estudo, foram mais elevadas nas parcelas adubadas com esterco (Tabela 2). Em média, nos sistemas CA e SA, o milho cultivado nas parcelas adubadas com esterco continha, em 2006, $233 \mathrm{e}$ $55 \%$ a mais nutrientes em relação ao controle e, 36 e $7 \%$ a mais, em relação às parcelas adubadas com gliricídia, respectivamente.

Em 2007 esses valores aumentaram para $263 \%$ dentro do sistema CA e $105 \%$ dentro do sistema SA quando comparados com o controle e para 124 e 59\% em relação àquelas parcelas adubadas com gliricídia.

A relação entre a quantidade de biomassa produzida por unidade de nutrientes absorvidos, ou seja, o coeficiente de utilização biológica (CUB) (Barros et al., 1989) variou em função da disponibilidade de nutrientes, tempo, tipo de sistema e tipo de adubação orgânica (Tabela 2).

Observou-se que em 2006, o CUB foi menor que no ano de 2007, período de menor disponibilidade de nutrientes. O sistema SA teve CUB maior que o sistema CA, indicando maior capacidade produtiva do primeiro em razão da maior competição por recursos (nutrientes e água) que ocorreu no CA. O CUB médio anual no sistema CA dos adubos orgânicos foi $\mathrm{E}>\mathrm{G}>\mathrm{C}$ e o $\mathrm{CUB}$ médio anual do sistema $\mathrm{SA}$ foi $\mathrm{E}>\mathrm{C}>\mathrm{G}$ (Tabela 2).

Em 2006, tanto no sistema SA quanto no CA, independente dos tratamentos de adubação, os nutrientes que apresentaram maior CUB foram $\mathrm{P}>\mathrm{Mg}$ e, em 2007, $\mathrm{Mg}>\mathrm{Ca}=\mathrm{P}$, respectivamente, o que sugere uma disponibilidade menor desses nutrientes nos tratamentos avaliados e, portanto, também menor efeito residual. Nesta condição, onde o solo mostrou deficiência de tais elementos sua exportação pode ser de maior relevância que a exportação total de nutrientes.

Sendo assim, a reposição de tais elementos é fundamental para a sustentabilidade desses sistemas agrícolas familiares.

\section{Teores de P, K, Ca E Mg no solo}

De maneira geral, os teores de $\mathrm{P}, \mathrm{K}, \mathrm{Ca}$ e $\mathrm{Mg}$ do solo em ambos os sistemas e ao longo dos dois anos do estudo, foram mais elevados nas parcelas adubadas com esterco, indicando o maior efeito residual desse tipo de adubo (Tabela 3 ).

Nos primeiro e segundo anos (2006 e 2007) após a última adubação orgânica com esterco, em ambos os sistemas os teores de $\mathrm{P}$ e $\mathrm{Ca}$ foram significativamente maiores que aqueles observados no controle (Tabela 3).

Em média, os teores de $\mathrm{P}$ nos primeiro ano e segundo anos no sistema CA, foram 266 e $120 \%$ maiores em relação ao controle e no sistema SA, 39 e 37\%, maiores que o controle, respectivamente. Em 2006, tanto no sistema CA quanto no SA, o teor de Ca nas parcelas adubadas com esterco foi em média 1,4 vezes maior em relação àquelas adubadas com gliricídia ou controle. Comportamento similar foi observado em 2007 (Tabela $3)$.

Os teores de P nas parcelas adubadas com gliricídia foram estatisticamente iguais aos teores encontrados entre o esterco e o controle, ao longo dos dois anos e sistemas avaliados, indicando menor efeito residual deste adubo. Os teores de $\mathrm{K}$ nas parcelas adubadas com esterco ou gliricídia, em ambos os sistemas avaliados, foram estatisticamente superiores ao controle apenas no primeiro ano (Tabela 3 ). Nos dois anos do estudo, os teores de $\mathrm{Mg}$ não diferiram significativamente entre os tratamentos de adubação orgânica e o controle.

\section{CONCLusões}

1. A adubação com esterco exerceu efeito residual significativo sobre a produtividade de biomassa do milho, absorção, acumulo de nutrientes e teores de nutrientes no solo, principalmente $\mathrm{Ca}$ e $\mathrm{Mg}$.

2. A adubação com biomassa de gliricídia não apresentou efeito residual significativo sobre a produtividade do milho, absorção, acumulo de nutrientes e teores de nutrientes no solo.

3. O efeito residual da adubação orgânica com esterco foi mais pronunciado no sistema de milho solteiro em relação ao sistema de milho consorciado com gliricídia. 


\section{AgradeCIMENTOS}

Os autores agradecem ao Instituto Interamericano de Pesquisas em Mudanças Globais (IAI-CRN2-014) pelo financiamento parcialmente concedido, e também, a AS-PTA no apoio para a realização das atividades de campo do presente estudo.

\section{LITERATURA CITADA}

Araújo, A. P.; Almeida, D. L. Adubação verde associada a fosfato de rocha na cultura do milho. Pesquisa Agropecuária Brasileira, v.28, p.245-251, 1993.

Barros, N. F.; Novais, R. F.; Carmo, D. N.; Neves, J. C. L. Classificação nutricional de sítios florestais: descrição de uma metodologia. Revista Árvore, v.10, p.112- 20, 1989.

EMBRAPA - Empresa Brasileira de Pesquisa Agropecuária. Informática agropecuária. Manual de análises químicas de solos, plantas e fertilizantes. 1.ed. Brasília: EMBRAPA, 1999. 370p.

Menezes, R. S. C.; Salcedo, I. H. Mineralização de N após incorporação de adubos orgânicos em um Neossolo Regolítico cultivado com milho. Revista Brasileira de Engenharia Agrícola e Ambiental, v.11, p.361-367, 2007.

Menezes, R. S. C.; Salcedo, I. H.; Elliott, E.T. Microclimate and nutrient dynamics in a silvopastoral system of semiarid northeastern Brazil. Agroforestry Systems, v.56, p.27-38, 2002.

Menezes, R. S. C.; Silva, T. O. Mudanças na fertilidade de um Neossolo Regolítico após seis anos de adubação orgânica. Revista Brasileira de Engenharia Agrícola e Ambiental, v.12, p.251-257, 2008.
Mundus, S.; Menezes, R. S. C.; Neergaard, A.; Garrido, M. S. Maize growth and soil nitrogen availability after fertilization with cattle manure and/or gliricidia in semiarid NE Brazil. Nutrient Cycling in Agroecosystems, v.82, p.6173, 2008.

Perez-Marin, A. M.; Menezes, R. S. C.; Salcedo, I. H. Produtividade de milho solteiro ou em aléias de gliricídia adubado com duas fontes orgânicas. Pesquisa Agropecuária Brasileira, v.42, n.5 p.669-677, 2007.

Perez-Marin, A. M.; Menezes, R. S. C.; Silva, E. D.; Sampaio E. V. S. B. Efeito da Gliricídia sepium sobre nutrientes do solo, microclima e produtividade do milho em sistemas agroflorestal no agreste paraibano. Revista Brasileira de Ciência do Solo, v.30, p.555-564, 2006.

Sampaio, E. V. S. B.; Salcedo, I. H.; Silva, F. B. R. Fertilidade de solos do semi-árido do Nordeste. In: Reunião brasileira de fertilidade dos solos e nutrição de plantas, 21, 1995, Petrolina. Anais... Insumo básico para a agricultura e combate à fome. Petrolina: Embrapa CPTSA/SBCS, 1995. p.51-71.

Sanchez, P. A. Science in agroforestry. Agroforestry Systems, v.30, p.5-55, 1995.

SAS Institute INC. SAS/STAT User's Guide. v.8.0. v.I, II and III. Cary: SAS Institute, Inc., 2000.

Silva, T. O.; Menezes, R. S. C.; Tiessen, H.; Sampaio, E. V. S. B.; Salcedo, I. H.; Silveira, L. M. Adubação orgânica da batata com esterco e, ou, crotalaria juncea. I.produtividade vegetal e Estoque de nutrientes no solo em longo prazo. Revista Brasileira de Ciência do Solo, v.31 p.39-49, 2007.

Tiessen, H.; Salcedo, I. H.; Sampaio, E. V. S. B. Nutrient and soil organic matter dynamics under shifting cultivation in semiarid Northeastern Brazil. Agriculture, Ecosytems and Environment, v.38, p.139-151, 1992. 